\title{
Comparison of methods to identify microglial cells and macrophages in the human central nervous system
}

\author{
MARGARET M ESIRI, JOHN BOOSS* \\ From the Department of Neuropathology, Radcliffe Infirmary, Oxford
}

SUMMARY The macrophage markers non-specific esterase, $\alpha_{1}$-antitrypsin, $\alpha_{1}$-antichymotrypsin, and lysozyme were compared with conventional microglial and macrophage stains in the human central nervous system. In a series of specimens from cases of head trauma, conventionally fixed and embedded, the modified Weil-Davenport stain was unequivocally best for demonstrating reactive microglia. $\alpha_{1}$-antichymotrypsin, however, was the most effective for showing macrophages in a series of specimens from patients with other conditions, which included inflammatory, neoplastic, and non-inflammatory diseases. The non-specific esterase reaction was unsatisfactory in tissues fixed in neutral formalin but was successful in fresh frozen tissue. In a series of specimens from cases of multiple sclerosis, non-specific esterase showed demyelination clearly and stained neuronal cytoplasm. It also stained macrophages but was less satisfactory for lipidbearing phagocytes in multiple sclerosis than oil red 0 .

Identification of lymphoreticular cells in tissue sections has recently been considerably improved by the use of immunohistological or histochemical techniques which enable cell specific marker molecules or enzymes to be detected. Thus histochemical techniques which show the presence of enzymes in macrophage or monocyte cytoplasm have been used to good effect. One such enzyme, non-specific esterase, has been shown in macrophages in sections of lymphoreticular organs such as tonsil and lymph node, lymphoreticular tumours, and smears or sections of pellets of peripheral blood monocytes. ${ }^{1-5}$ Lysozyme, $\alpha_{1}$-antitrypsin, and $\alpha_{1}$-antichymotrypsin have likewise been shown immunohistologically in macrophage cytoplasm in tissue sections..$^{6-8}$

Macrophages in the central nervous system respond to tissue damage, invasion by foreign antigens, and the presence of neoplasia. Many of these macrophages clearly originate from blood borne monocytes and invade the central nervous system parenchyma via a vascular route. Other phagocytes may arise from microglia resident in the brain which are mobilised in the presence of injury. ${ }^{9}$ These cells

Accepted for publication 19 October 1983

*On leave from the Neurology Service, VA Medical Center, West Haven, Ct. are well visualised by the use of silver stains such as the Weil-Davenport stain. ${ }^{10}$ Whether the cells which have putatively evolved from microglia can also function in the other ways that macrophages do is not clear. It would be of considerable potential benefit in understanding the pathogenesis of several diseases of the central nervous system to know if the enzyme markers used for identifying macrophages in other tissues can also be applied to macrophages in the central nervous system, whether these are of recent vascular or microglial origin.

In this paper we describe the investigation of various recently introduced methods to identify macrophages in the central nervous system, compare these with standard microglial and macrophage stains, and describe their limitations.

\section{Material and methods}

\section{TISSUES}

Tonsil

Samples of tonsil obtained at routine tonsillectomy were studied to establish conditions of fixation and staining for various procedures and to provide control tissue containing macrophages which has been well studied by other workers. Fresh frozen cryostat sections and formalin-paraffin, and formalin-frozen sections were prepared from this tissue. 
Central nervous system

Cases of head injury. Cerebral tissue from 10 patients dying after severe head trauma were studied. The advantage of using such material is that the time of injury (and therefore the response to injury in the brain) can be precisely identified. We considered that the lesions containing microglial clusters originated from the time of injury. In the cases studied the times of injury to death ranged from $16 \mathrm{~h}$ to 13 days. Brains were fixed by suspension in neutral formalin for three to four weeks. Tissue blocks from areas adjacent to contusions or from the corpus callosum (known to be at risk in head injury) were divided for paraffin embedding and frozen sectioning. The time of appearance and ease of discrimination of several cell forms were investigated and compared with each of the stains used: (1) in glial nodules containing microglial cells in various forms-small cells with sparse short processes, slightly larger cells with more elongated processes, and cells with more cytoplasm (sometimes honeycombed) and processes; (2) in phagocytic or "Gitter" cells in parenchyma, perivascular spaces, subarachnoid space, or areas of necrosis.

Cases of other neurological disease. Central nervous system tissue obtained at necropsy, formalin fixed or fresh frozen, or both, was studied from patients with a variety of central nervous system diseases. Forma- lin fixed material was examined mainly in paraffin sections. Conditions studied in formalin fixed material included acute (pyogenic), tuberculous, and cryptococcal meningitides; brain granuloma; acute disseminated encephalomyelitis; herpes simplex virus encephalitis; cerebral lymphoma; adrenoleucodystrophy; and multiple sclerosis. Fresh frozen cryostat sections were examined from cases of multiple sclerosis and the following non-inflammatory conditions: Alzheimer's disease, Huntington's disease, Parkinson's disease, and amyotrophic lateral sclerosis.

\section{STAINS}

The following procedures were carried out on $8 \mu \mathrm{m}$ formalin-paraffin sections: histochemical technique for non-specific esterase ( $\alpha$-naphthyl acetate esterase method with haematoxylin counterstain); ${ }^{\prime \prime}$ haematoxylin and eosin; immunoperoxidase techniques for $\alpha_{1}$-antitrypsin, ${ }^{8} \alpha_{1}$-antichymotrypsin, ${ }^{7}$ and lysozyme. ${ }^{6}$ Antisera were obtained from Dakopatts and used at a dilution of $1 / 1000$ with and without preceding trypsin treatment $(0.1 \%$ solution in Tris saline with $0.1 \% \mathrm{CaCl}_{2}(\mathrm{pH} 7.4)$ for $40 \mathrm{~min}$ at $37^{\circ} \mathrm{C}$ ). Control sections were treated with normal rabbit serum or with specific antisera preabsorbed with antigen. The following stains were applied to $20 \mu \mathrm{m}$ formalin fixed frozen sections: oil red 0 and

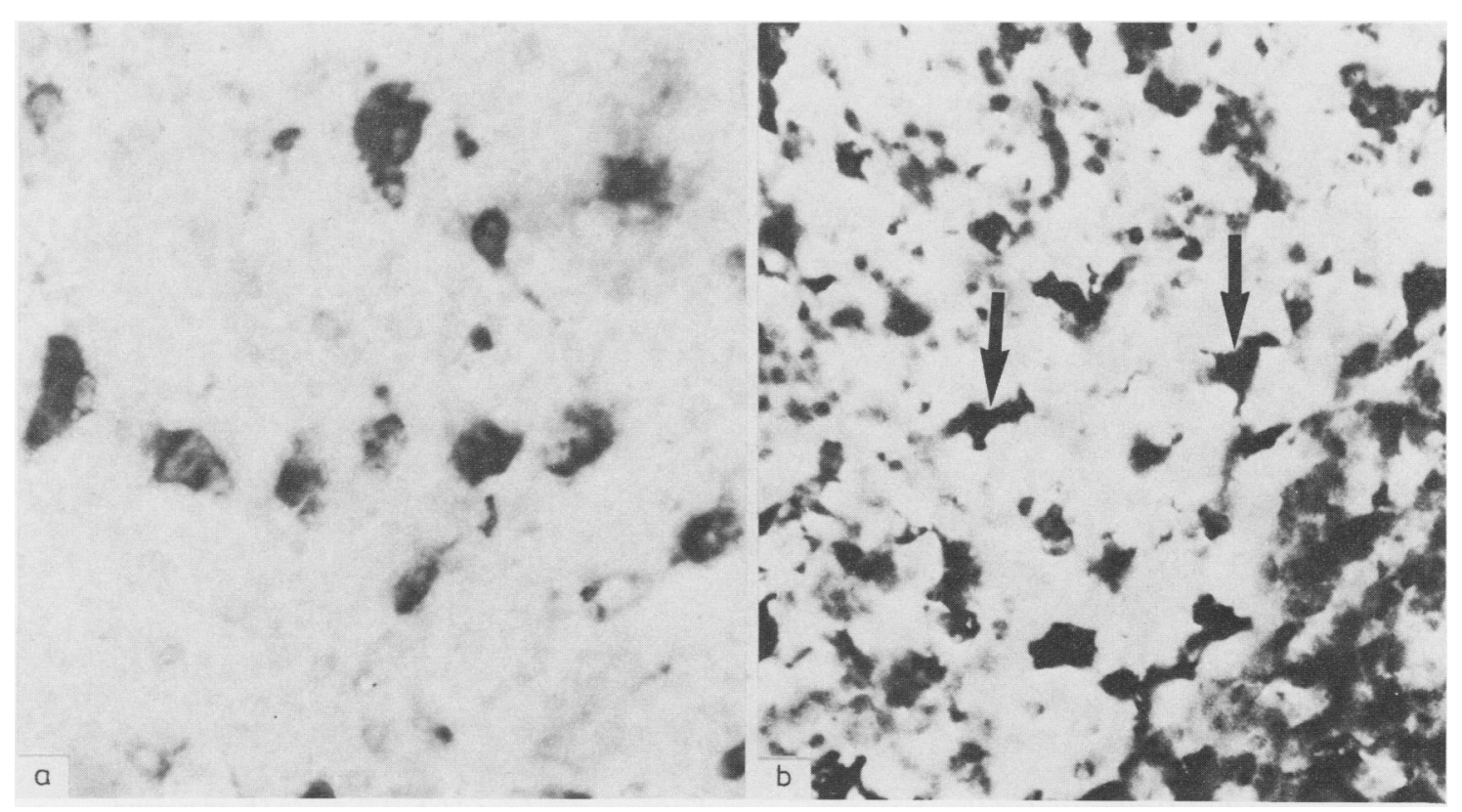

Fig. 1 (a) Fresh frozen section of tonsil germinal centre showing non-specific esterase activity in macrophages. Counterstained with haematoxylin $\times 500$. (b) Tonsil germinal centre showing staining of cells with Weil-Davenport stain. Stained cells (arrows) are comparable to those shown by the non-specific esterase reaction $\times 500$. 
modified Weil-Davenport. ${ }^{12}$ On $8 \mu \mathrm{m}$ fresh frozen cryostat sections non-specific esterase ( $\alpha$-naphthyl acetate esterase) and oil red 0 stains were investigated.

\section{Results}

TONSIL

Non-specific esterase activity was well visualised in macrophages measuring $20-50 \mu \mathrm{m}$ in diameter in germinal follicles in fresh frozen sections of tonsil, as described by Crocker 5 (Fig. 1a). Fixation in neutral formalin resulted in loss of demonstrable activity. Although formol-calcium is the recommended fixative, we used neutral formalin because we wished to investigate the value of the stain in routinely processed material.

Far fewer follicular macrophages reacted positively for $\alpha_{1}$-antichymotrypsin compared with nonspecific esterase. About the same number or slightly fewer cells reacted for $\alpha_{1}$-antitrypsin as for $\alpha_{1-}$ antichymotrypsin, but the reaction product was much less intense. With anti-lysozyme antibody there were fewer reacting cells and the reaction product was weak. The intensity of reaction with these antibodies appeared to change little, if at all, after treating the sections with trypsin.
The Weil-Davenport stain showed large (20$50 \mu \mathrm{m})$ heavily stained cells in germinal follicles. These appeared to be equivalent in size, distribution, and number to the follicular macrophages detected by the non-specific esterase reaction (Fig. $1 b)$.

\section{CENTRAL NERVOUS SYSTEM \\ Cases of head trauma}

The Weil-Davenport stain showed scanty small microglial cells with short processes $16-20 \mathrm{~h}$ after injury. These cells were undetectable with antibodies to $\alpha_{1}$-antichymotrypsin, $\alpha_{1}$-antitrypsin, and lysozyme or with any of the other stains used. In the cases examined two to four days after injury the Weil-Davenport stain showed a few microglia, which were slightly larger and with more processes than those seen earlier. These cells were also negative for $\alpha_{1}$-antichymotrypsin, $\alpha_{1}$-antitrypsin, and lysozyme. There were occasional mononuclear cells in perivascular spaces, which reacted positively for $\alpha_{1}$-antichymotrypsin at this stage. These cells were less strongly reactive for $\alpha_{1}$-antitrypsin and lysozyme. The appearance of similarly positioned cells with the haematoxylin and eosin stain suggested that they were macrophages. Lysozyme and

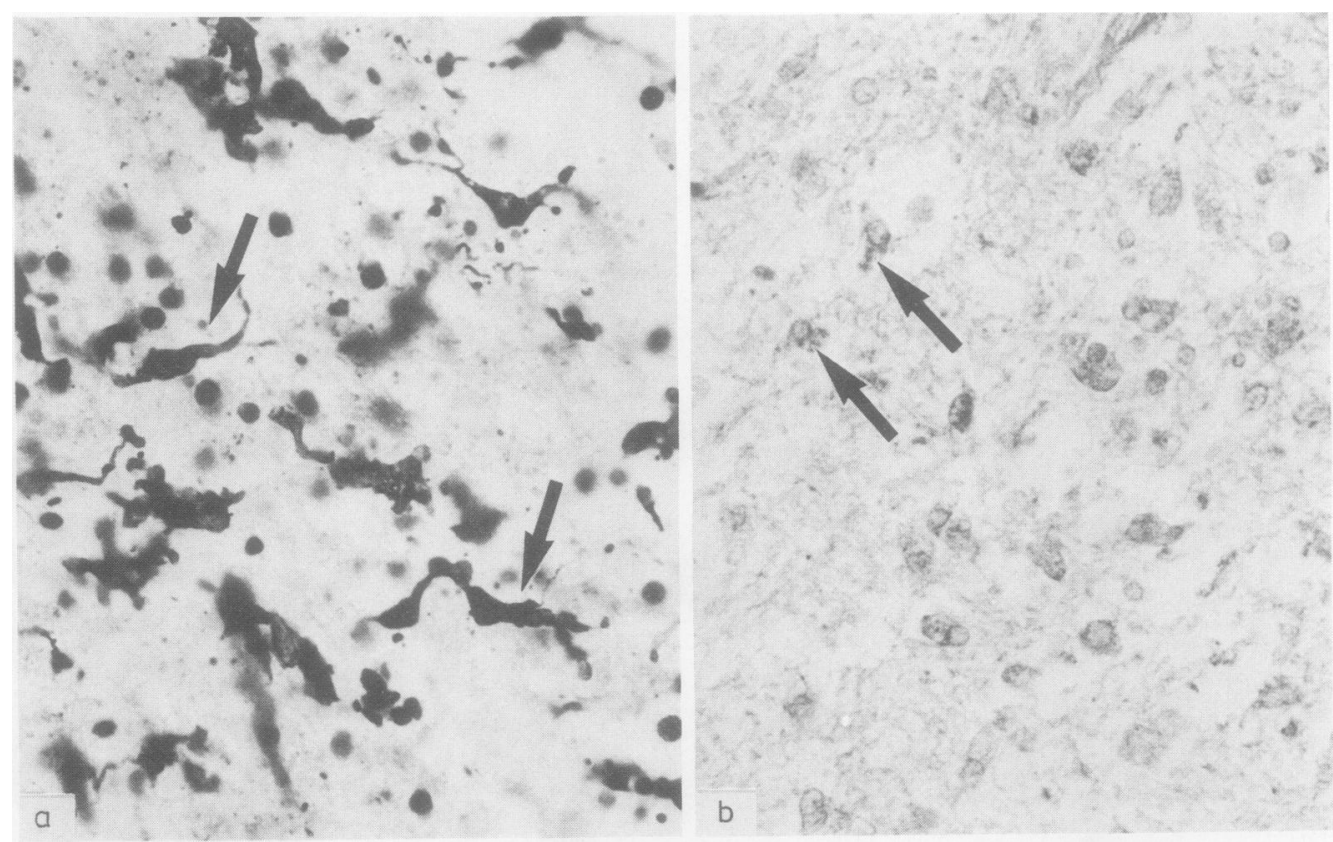

Fig. 2 (a) Weil-Davenport stain showing reactive microglia (arrows) in frontal lobe in a case of head trauma with 13 days' survival $\times 500$. (b) Adjacent area to (a) from paraffin section treated with anti- $\alpha_{1}$-antichymotrypsin antibody. Barely positive reaction is present in cells (arrows) comparable to those seen in (a). Counterstained with haematoxylin $\times 500$. 
$\alpha_{1}$-antitrypsin, but not $\alpha_{1}$-antichymotrypsin, were detectable in scanty neutrophils also at this stage. In tissue from patients who survived for six to 13 days after injury the Weil-Davenport stain showed well defined clusters of enlarged, plump bodied microglia with elongated processes. These cells gave a weakly positive reaction for $\alpha_{1}$-antichymotrypsin and inconsistent, even weaker reactions for $\alpha_{1}$-antitrypsin and lysozyme (Fig. 2). Gitter cells and lipid-containing macrophages were seen with haematoxylin and eosin and oil red 0 stains respectively at this stage. These cells gave a positive reaction for $\alpha_{1-}$ antichymotrypsin and to a lesser extent for $\alpha_{1}$ antitrypsin and lysozyme.

\section{Cases of other neurological diseases}

In the material examined after formalin fixation and paraffin embedding the main findings relate to the use of the $\alpha_{1}$-antichymotrypsin, $\alpha_{1}$-antitrypsin and lysozyme antibodies. The strongest reactions with these antibodies were found in the macrophages present in the subarachnoid space in chronic meningitis and in brain parenchyma in acute encephalitis. Of the three antibodies anti- $\alpha_{1}$-antichymotrypsin gave the most satisfactory results in all conditions. In chronic meningitis there was a strong positive reaction for $\alpha_{1}$-antichymotrypsin in the cytoplasm of some, but not all, Gitter cells and most epithelioid cells, and there was a weak reaction in the cytoplasm

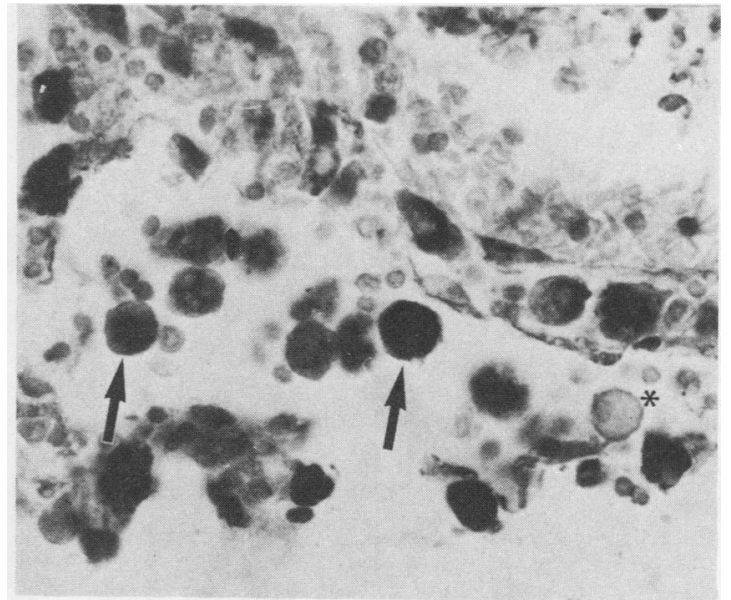

Fig. 3 Macrophages in the subarachnoid space from a case of tuberculous meningitis. Paraffin section treated with anti- $\alpha_{1}$-antichymotrypsin antibody. Many macrophages show a positive reaction in the cytoplasm (examples arrowed). The intensity of reaction is variable from cell to cell and some Gitter cells are negative $\left({ }^{*}\right)$. Counterstained with haematoxylin $\times 800$.

of some, but not all multinucleate giant cells. Positive and negative reactions were sometimes obtained in neighbouring cells with similar morphological appearances (Fig. 3). In chronic mening-

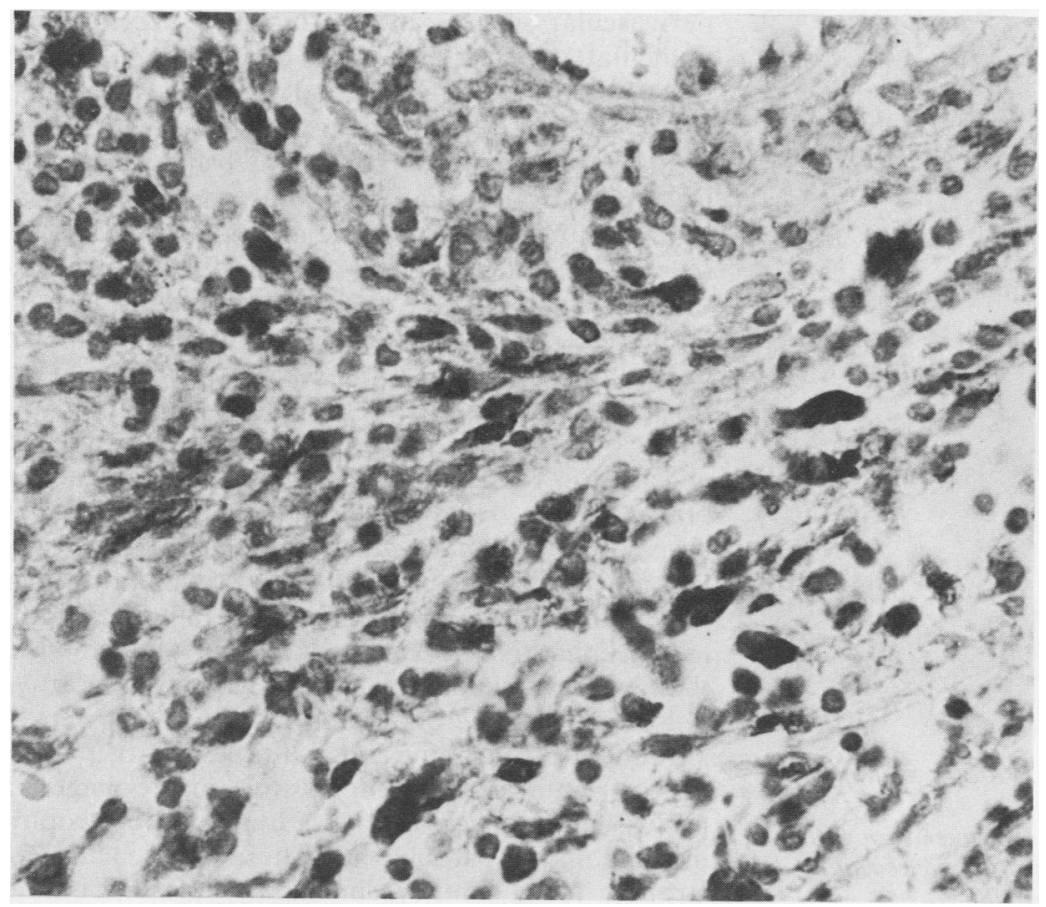

Fig. 4 Inflammatory in filtrate in subarachnoid space from a case of tuberculous meningitis. Paraffun section treated with anti- $\alpha_{1}$-antichymotrypsin antibody. Many cells including epithelioid cells have cytoplasm which reacts positively. Counterstained with haematoxylin $\times 800$. 


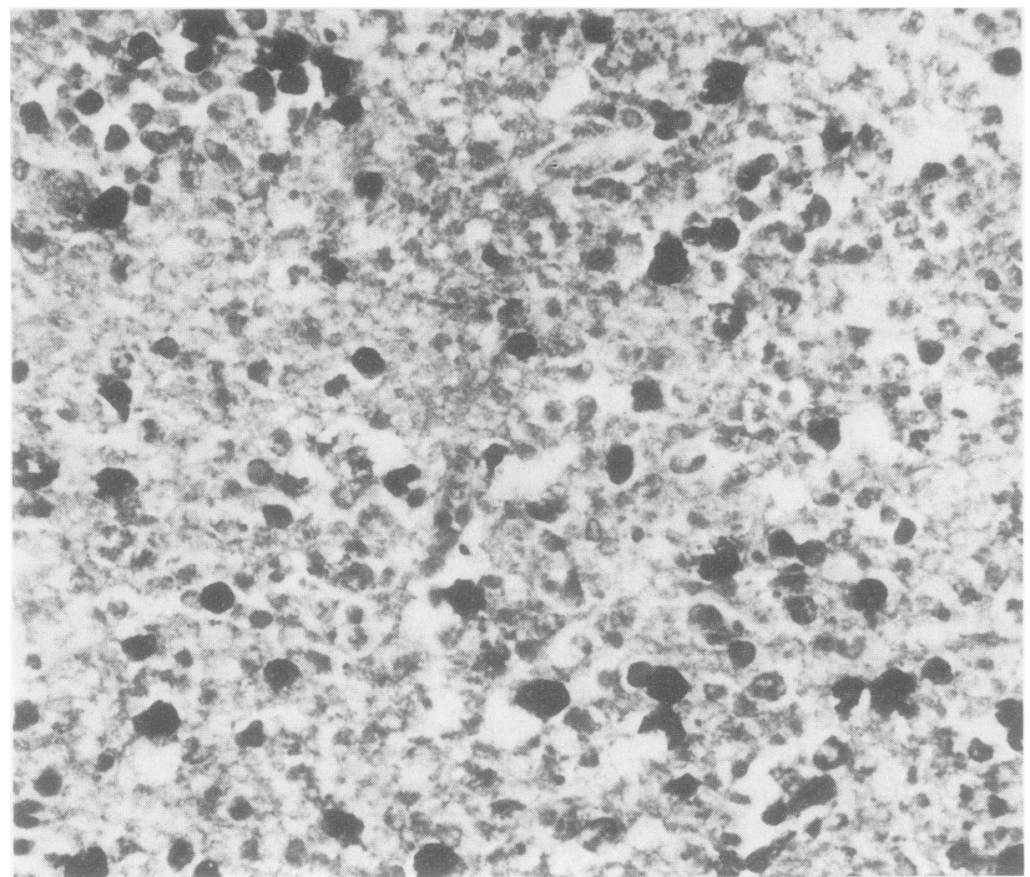

Fig. 5 Inflammatory infiltrate in cerebral cortex from a case of herpes simplex encephalitis. Paraffin section treated with anti- $\alpha_{1}$-antichymotrypsin antibody. Many Gitter cells show positive cytoplasmic reaction. Counterstained with haematoxylin $\times 500$.

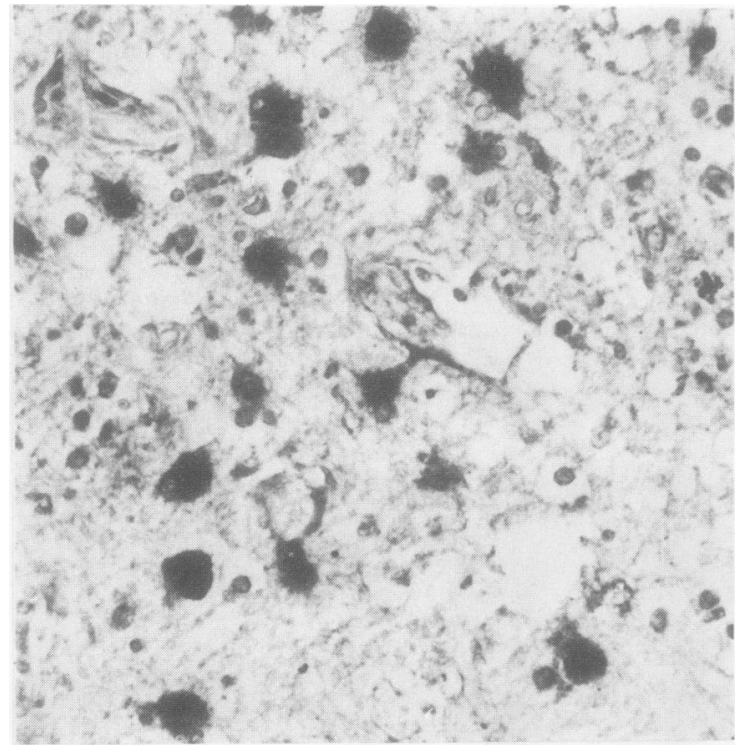

Fig. 6 Case of cerebral lymphoma. Paraffin section from the edge of the tumour treated with anti- $\alpha_{1}$-antichymotrypsin antibody. Reactive astrocytes give a positive but non-specific diffuse cytoplasmic reaction. Counterstained with haematoxylin $\times 500$. itis positively reacting cells were present in well defined granulomas and more diffusely within the subarachnoid space (Fig. 4), ependymal regions, perivascular spaces, and in damaged parenchyma. Some flattened spindle shaped cells in the pia and in the adventitial layer of blood vessels also reacted positively for $\alpha_{1}$-antichymotrypsin. Cytoplasmic staining varied considerably in intensity, was granular in appearance, and was sometimes confined to perinuclear regions. In acute meningitis neutrophils reacted positively for lysozyme and $\alpha_{1}$-antitrypsin, but not usually for $\alpha_{1}$-antichymotrypsin. In a brain granuloma of undetermined aetiology the zone of epithelioid cells gave a moderately strong reaction for $\alpha_{1}$-antichymotrypsin (less strong for $\alpha_{1 \text { - }}$ antitrypsin and lysozyme). In acute disseminated encephalomyelitis there were a few cells reacting positively for $\alpha_{1}$-antichymotrypsin in perivascular spaces and the subarachnoid space and occasionally in the parenchyma, but most mononuclear inflammatory cells were unreactive. In herpes simplex encephalitis with two weeks' survival from onset there were abundant $\alpha_{1}$-antichymotrypsin positive Gitter cells in necrotic cerebral cortex (Fig. 5). In adrenoleucodystrophy and multiple sclerosis there were $\alpha_{1}$-antichymotrypsin positive macrophages in perivascular spaces and, in adrenoleucodystrophy, in white matter parenchyma. These cells reacted less strongly for $\alpha_{1}$-antitrypsin and lysozyme. Tumour 


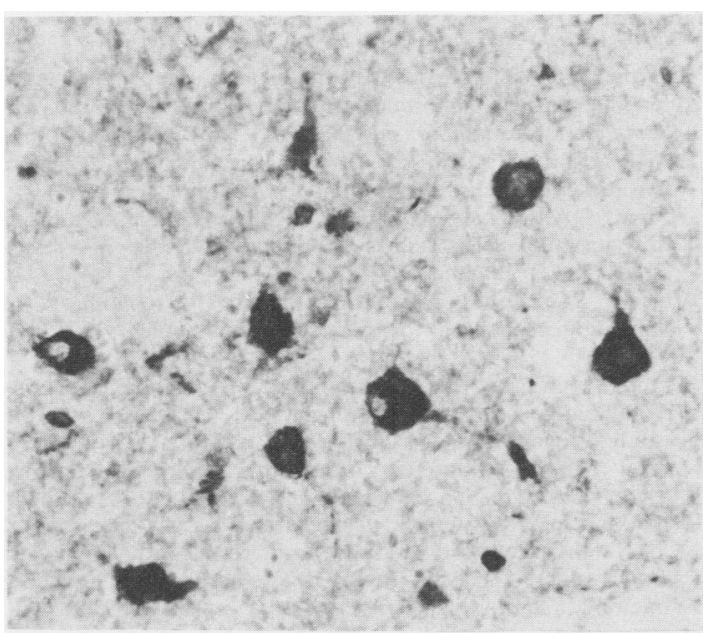

Fig. 7 Low power view of fresh frozen section of thalamus from a case of multiple sclerosis showing non-specific esterase activity in cytoplasm of large neurones. Counterstained with haematoxylin $\times 350$.

cells of the cerebral lymphoma were negative for all the macrophage marker enzymes studied.

In addition to staining of macrophages described above there was a considerable degree of staining of other cellular elements which was presumed to be non-specific. Heavy background staining of almost all tissue was seen in areas of necrosis, and in other areas astrocytes, particularly reactive astrocytes, gave a strong positive reaction for $\alpha_{1-}$ antichymotrypsin (Fig. 6), $\alpha_{1}$-antitrypsin, and lysozyme. Swollen oligodendrocyte cytoplasm in a few cases of head injury also stained weakly for $\alpha_{1}$-antichymotrypsin. In autolysed tissue neuronal cytoplasm and nuclei also reacted strongly. The staining of all these structures was diffuse rather than granular as in macrophages, but on occasion it could give rise to confusion.

Fresh frozen sections stained for non-specific esterase activity in multiple sclerosis showed a surprisingly clear demarcation of demyelination. Macrophages gave a weakly positive reaction. Lipidcontaining macrophages were generally shown more successfully in sections stained with oil red 0 . In grey matter neuronal cytoplasm gave a strikingly positive reaction which made detection of parenchymal macrophages difficult (Fig. 7). This neuronal reaction was particularly prominent in large neurones of basal ganglia, thalamus, pontine nuclei, and spinal cord anterior horns. As in the tonsil, we were unable to obtain a positive reaction for non-specific esterase after formalin fixation.

\section{Discussion}

It seems from the present study of cases of head injury that none of the enzyme markers for macrophages used here was as satisfactory as the WeilDavenport stain for identifying reacting microglial cells of the type that appear in the lesions after head injury described by Oppenheimer. ${ }^{12}$ It was only at the latest stage at which we examined these lesions (two weeks after injury) that we obtained a weakly positive reaction for $\alpha_{1}$-antichymotrypsin in these cells, and antibodies to $\alpha_{1}$-antitrypsin and lysozyme were even less satisfactory at showing them. We have therefore failed to find convincing similarities with regard to content of these enzymes between reacting, Weil-Davenport positive microglial cells and conventional macrophages. Oemichen et al ${ }^{13}$ failed to obtain a reaction for human resting microglia with an antibody raised against human myelomonocytic cells, but studies comparable with the present one on human reactive microglia have not been performed. The mechanism of action of the Weil-Davenport stain in demonstrating microglia is not understood, but appearances of the stained cells suggest that the stain may be deposited on the cell membranes. It is of interest that the same stain gave strongly positive results on tonsillar macrophages, which are strongly non-specific esterase positive but only a few of which gave a positive reaction for $\alpha_{1}$-antichymotrypsin, $\alpha_{1}$-antitrypsin, and lysozyme. It is possible that the Weil-Davenport stain precipitates on the membranes of cells which have the capacity to produce these enzymes. The related question of whether reacting microglial cells show non-specific esterase reactivity is one that we did not investigate in this study. The question may be difficult to answer at the level of resolution offered by light microscopy because of the limited amount of cytoplasm in many microglial forms.

The widespread use of non-specific esterase as a monocyte-macrophage marker prompted this study of its application to the central nervous system. It worked well on fresh frozen material but not on material routinely fixed in formaldehyde and paraffin embedded. When used with haematoxylin it provided unexpectedly good resolution of demyelination. The oil red 0 stain, however, was more satisfactory in detecting lipid-containing phagocytes. Furthermore, although macrophages were identified, care had to be exercised because of the strong cytoplasmic reaction of neurones. These observations suggest that the application of the non-specific esterase reaction to the central nervous system needs further study.

In the study of inflammatory conditions the $\alpha_{1-}$ antichymotrypsin antibody was clearly superior to 
the $\alpha_{1}$-antitrypsin or lysozyme antibodies to demonstrate macrophages. The reaction was more intense for $\alpha_{1}$-antichymotrypsin than for the other two enzymes, and, in addition, $\alpha_{1}$-antichymotrypsin, unlike $\alpha_{1}$-antitrypsin and lysozyme, was generally absent from neutrophils. Trypsin pretreatment of sections did not appear to enhance reactions reliably with any of these antibodies. Macrophages differed considerably in the intensity of their reaction with these antibodies. This may reflect differences in enzyme content or accessibility to react. Isaacson et $a l^{8}$ have produced evidence that $\alpha_{1}$-antitrypsin is synthesised in macrophages, and the amount of enzyme may well vary with the state of activity or exhaustion of the cells. Papadimitriou et al ${ }^{7}$ considered that the intensity of immunostaining of macrophages for $\alpha_{1}$-antichymotrypsin correlated with their phagocytic activity.

We conclude that the $\alpha_{1}$-antichymotrypsin antibody may be useful in distinguishing macrophages from other mononuclear inflammatory cells in the central nervous system. Non-specific staining of glial and in some circumstances, neuronal, elements needs to be taken into account when these antibodies are used as macrophage markers, but the morphological differences between macrophages and the other cells usually suffice to distinguish them. There remains a need, however, for a specific macrophage marker such as one detectable with a monoclonal antibody, perhaps comparable to the one recently described as specific for murine macrophages. ${ }^{14}$

Miss Margaret Reading provided excellent technical assistance. This study was financially supported by the Multiple Sclerosis Society of Great Britain and Northern Ireland.

\section{References}

' Dorfman RF. Enzyme histochemistry of normal, hyperplastic and neoplastic lymphoreticular tissues. In: Roulet FC, ed. The lymphoreticular tumours in Africa. New York: S Karger, 1964.

${ }^{2} \mathrm{Li}$ CY, Lam KW, Yam LT. Esterases in human leucocytes. $J$ Histochem Cytochem 1973;21:1-12.

${ }^{3}$ Horwitz DA, Allison AC, Ward'P, Knight N. Identification of human mononuclear leucocyte populations by esterase staining. Clin Exp Immunol 1977;30:289-98.

${ }^{4}$ Curran RC, Jones EL. Non-Hodgkin's lymphomas: an immunohistochemical and histological study. $J$ Path 1979;129:179-90.

${ }^{5}$ Crocker $J$. The enzyme histochemistry of lymphoid and nonlymphoid cells of the human palatine tonsil: a basis for the study of lymphomas. J Pathol 1980;134:81-95.

- Mason DY, Taylor CR. The distribution of muramidase (lysozyme) in human tissues. J Clin Pathol 1975;28:124-32.

' Papadimitriou CS, Stein H, Papacharalapous NX. Presence of $\alpha$-1-antichymotrypsin and $\alpha$-1-antitrypsin in haemopoietic and lymphoid cells as revealed by the immunoperoxidase method. Pathology, research, and practice 1980;169:287-97.

${ }^{8}$ Isaacson P, Jones DB, Millward-Sadler GH, Judd MA, Payne S. Alpha-1-antitrypsin in human macrophages. $J$ Clin Pathol 1981;34:982:90.

${ }^{9}$ Brierley JB, Brown HW. The origin of lipid phagocytes in the central nervous system: 1 The intrinsic microglia. J Comp Neurol 1982;211:397-406.

${ }^{10}$ Weil A, Davenport HA. Staining of oligodendroglia and microglia in celloidin sections. Arch Neurol Pschiat 1933;30:175-8.

" Bancroft JD. Histochemical techniques. 2nd ed. London: Butterworth, 1975: 254

${ }^{12}$ Oppenheimer DR. Microscopic lesions in the brain following head injury.J Neurol Neurosurg Psychiatry 1968;31:299-306.

${ }^{13}$ Oemichen $M$, Wietholter $H$, Greaves MF. Immunological analysis of human microglia: lack of monocytic and lymphoid membrane differentiation. J Neuropath Exp Neurol 1979;38:99-103.

${ }^{14}$ Hume DA, Gordon S. Mononuclear phagocyte system of the mouse defined by immunohistochemical localisation of antigen F4/80. J Exp Med 1983;157:1704-9.

Requests for reprints to: Dr Margaret M Esiri, Department of Neuropathology, The Radcliffe Infirmary, Oxford $\mathrm{OX} 26 \mathrm{HC}$, England. 